\title{
Ophthalmic Solution Dosage Form
}

National Cancer Institute

\section{Source}

National Cancer Institute. Ophthalmic Solution Dosage Form. NCI Thesaurus. Code

C91163.

A solution intended for administration in or around the eye. 